\title{
From dimethylamine to pyrrolidine: the development of an im- proved nickel pincer complex for cross-coupling of non-activated secondary alkyl halides
}

\author{
Pablo M. Perez Garcia, ${ }^{\ddagger}$ Thomas Di Franco, ${ }^{\ddagger}$ Alexandre Epenoy, Rosario Scopelliti and Xile Hu*
}

Laboratory of Inorganic Synthesis and Catalysis, Institute of Chemical Sciences and Engineering, École Polytechnique Fédérale de Lausanne (EPFL), 1015 Lausanne, Switzerland

\begin{abstract}
Replacement of a dimethyl amino group of the amidobis(amine) nickel (II) pincer complex (1), [( $\left.\left.{ }^{\mathrm{Me}} \mathrm{N}_{2} \mathrm{~N}\right) \mathrm{Ni}-\mathrm{Cl}\right]$, by a pyrrolidino group resulted in a new nickel (II) pincer complex (2), [( $\left.\left.{ }^{\mathrm{Pyr}} \mathrm{N}^{\mathrm{Me}} \mathrm{NN}\right) \mathrm{Ni}-\mathrm{Cl}\right]$. Complex 2 is an efficient catalyst for Kumada and Suzuki-Miyaura cross-coupling of non-activated secondary alkyl halides, while complex $\mathbf{1}$ is largely inactive. The significant activity difference is tentatively attributed to a minimal structural difference, which leads to a more hemilabile ligand.

KEYWORDS: Nickel, Pincer Ligands, Kumada coupling, Suzuki-Miyaura coupling, Secondary alkyl halide
\end{abstract}

Cross-coupling reactions have become one of the most powerful synthetic methodologies. ${ }^{1}$ However, the coupling of non-activated alkyl halides, especially secondary alkyl halides, is challenging due to their reluctance to oxidative addition and the tendency of metal alkyl intermediates to undergo unproductive $\beta$-hydride elimination. ${ }^{2}$ By judicious choices of metal, ligand, and reaction condition, many catalytic systems have recently been developed for the cross-coupling of nonactivated alkyl halides. ${ }^{3-7}$
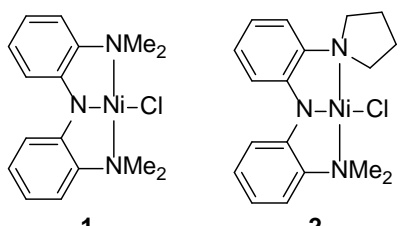

Figure 1. Amido bis(amine) pincer complexes 1 and 2.

The majority of these systems are developed by ligandscreening, and the active catalysts are often unidentified. In an alternative approach, we have developed a well-defined nickel pincer complex, Nickamine (1, Figure 1), which is an unusually general catalyst for a large number of cross-coupling ${ }^{8-10}$ and related $\mathrm{C}-\mathrm{H}$ functionalization ${ }^{11}$ reactions of non-activated alkyl halides. The modularity of the pincer ligand system allows for systematic modifications, an important tool for rational improvement of catalysts. ${ }^{12}$ While $\mathbf{1}$ is very efficient for the coupling of primary alkyl halides, it has low activity for the coupling of secondary alkyl halides. Here, we report that the seemingly insignificant change of one pair of dimethyl groups of 1 into a 1,4-butanediyl group has led to a dramatic improvement in catalytic activity. The new pincer complex 2 (Figure 1) is an excellent catalyst for Kumada and SuzukiMiyaura coupling of secondary alkyl halides.

The new pincer proligand 3 was prepared in a good yield by Pd-catalyzed C - N coupling of 2-(pyrrolidin-1-yl)aniline and 2-bromo- $N, N$-dimethylaminobromobenzene (Scheme 1$)$.

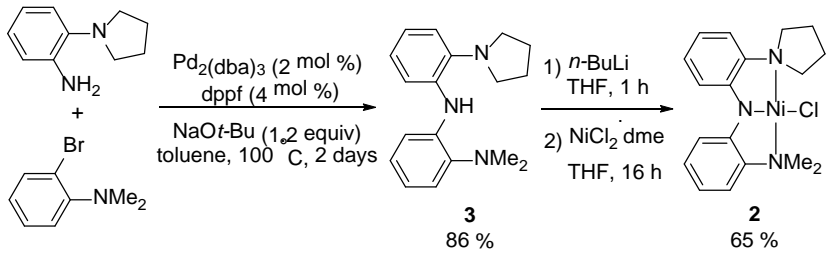

Scheme 1. Synthesis of the New Pincer Complex 2

The proligand was then lithiated by $n$-BuLi, followed by treatment with $\mathrm{NiCl}_{2} \cdot \mathrm{dme}$, to give the $\mathrm{Ni}(\mathrm{II})$ pincer complex 2 . The molecular structure of $\mathbf{2}$ was determined by single-crystal diffraction study (Figure 2). ${ }^{13}$

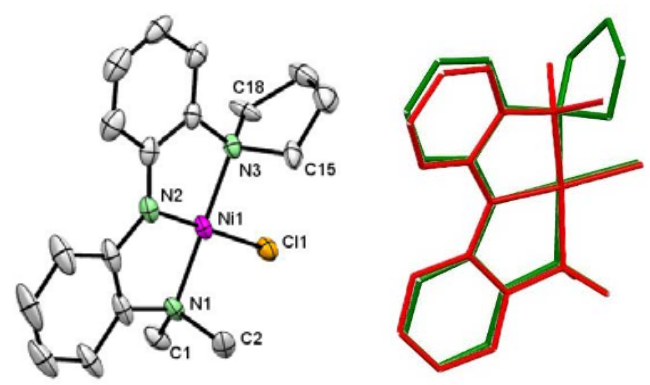

Figure 2. (Left) Crystal structure of complexes 2. Hydrogens atoms are omitted for clarity. (Right) Overlapping of the crystal structure of $\mathbf{1}$ (in red) with the crystal structure of $\mathbf{2}$ (in green)

The Ni ion is in the expected square-planar coordination geometry. The structural parameters of $\mathbf{2}$ are very similar to those of 1 (Figure 2 and Table 1). The corresponding Ni-N and $\mathrm{Ni}-\mathrm{Cl}$ bond lengths have a difference of no more than $0.019 \AA$ between 1 and 2 . Likewise, the corresponding bond angles around the $\mathrm{Ni}$ ions have the difference of no more than $0.49^{\circ}$. Only the pyrrolidino group in $\mathbf{2}$ and the dimethylamino group in $\mathbf{1}$ exhibit appreciable structural difference: the C-N-C angle in the pyrrolidino group is $4.2^{\circ}$ smaller than its counterpart in the dimethylamino group. This contraction of the $\mathrm{C}-\mathrm{N}-\mathrm{C}$ angle 
in $\mathbf{2}$ is consistent with the steric property of the pyrrolidino group.

Table 1. Comparison of Key Structural Parameters between Complexes 2 and 1

\begin{tabular}{|c|c|c|c|}
\hline Entry & Selected Units & $\begin{array}{l}\text { Length }(\AA) \text { or } \\
\text { Angle }\left(^{\circ}\right)\end{array}$ & $\begin{array}{l}\text { Corresponding } \\
\text { Length }(\AA) \text { or } \\
\text { Angle }\left(^{\circ}\right) \text { in } \mathbf{1}\end{array}$ \\
\hline 1 & Ni1-Cl1 & 2.2130 (13) & $2.2029(7)$ \\
\hline 2 & Ni1-N1 & $1.963(4)$ & 1.9598 (19) \\
\hline 3 & Ni1-N2 & $1.854(4)$ & $1.835(2)$ \\
\hline 4 & Ni1-N3 & $1.968(4)$ & $1.956(2)$ \\
\hline 5 & N1-Ni1-N2 & 86.76 (18) & 86.64 (8) \\
\hline 6 & N1-Ni1-Cl1 & $92.9(1)$ & 93.59 (6) \\
\hline 7 & N2-Ni1-N3 & 86.02 (17) & 85.89 (9) \\
\hline 8 & N3-Ni1-Cl1 & $94.3(1)$ & 94.49 (6) \\
\hline 9 & C1-N1-C2 & $108.1(4)$ & $108.4(2)$ \\
\hline 10 & Ni1-N3-C15 & $118.5(3)$ & $112.4(1)$ \\
\hline 11 & Ni1-N3-C18 & $103.3(3)$ & $108.9(2)$ \\
\hline 12 & C15-N3-C18 & $104.7(4)$ & $108.9(2)$ \\
\hline
\end{tabular}

The catalytic activity of complex 2 was first probed in the Kumada coupling reactions. The coupling of 1-iodooctane with butylmagnesium chloride, and the coupling of 1iododecane with phenylmagnesium chloride, were used as the test reactions (Scheme 2, Eq. 1 and 2). The previously optimized conditions for complex 1 were employed. ${ }^{8 \mathrm{a}-8 \mathrm{~b}}$ High yields of cross-coupling were obtained using $3.5 \mathrm{~mol} \%$ of 2 as catalyst. The yields are comparable to those using $\mathbf{1}$ as catalyst. The catalyst loading could be decreased to $1 \mathrm{~mol} \%$ without influencing the yield for catalyst 2, but not for catalyst $\mathbf{1}$ (Table S1 and Figure S1). This result suggests a higher activity of 2 .

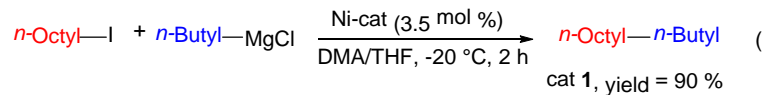

$$
\begin{aligned}
& \begin{array}{l}
\text { cat } 1 \text {, yield }=90 \% \\
\text { cat } 2 \text {, yield }=96 \%
\end{array} \\
& \begin{array}{l}
n \text {-Decyl_L } \\
\begin{array}{l}
\text { TMEDA (30 mol \%) } \\
\text { THF, } 2 \mathrm{~h}
\end{array}
\end{array} \begin{array}{l}
\text { cat 1, yield }=83 \% \\
\text { cat 2, yield }=80 \%
\end{array}
\end{aligned}
$$

Scheme 2. Test Reactions for Kumada Cross-Coupling Using 1 or 2 as Catalyst

Complex 2 was then applied for the coupling of various functionalized primary and cyclic secondary alkyl halides (Table 2). ${ }^{14}$ Good yields were obtained in many cases. Functional groups such as ester (Table 2, Entry 1), nitrile (Table 2, Entry 2), trifluoromethyl (Table 2, Entry 3), furane and tetrahydropyrane were tolerated (Table 2, Entries 4-5 and 12). Cyclohexyl halides were also coupled (Table 2, Entries 67 and 13). Both alkyl-alkyl and alkyl-aryl coupling were successful. These results are somewhat expected since previous work shows that analogous catalyst $\mathbf{1}$ was active for the coupling of these substrates.

Table 2. Kumada Coupling of Primary Alkyl and Cyclo-

\begin{tabular}{|c|c|c|c|}
\hline Entry & Alkyl Halide & Grignard Reagent & Yield (\%) \\
\hline 1 & & n-Octyl-MgCl & $70^{b}$ \\
\hline 2 & & n-Butyl-MgCl & $60^{b}$ \\
\hline 3 & & n-Octyl-MgCl & $63^{b}$ \\
\hline 4 & & n-Octyl-MgCl & $79^{b}$ \\
\hline 5 & $\mathrm{Ph}$ & n-Butyl-MgCl & $80^{b}$ \\
\hline 6 & & n-Butyl-MgCl & $\begin{array}{l}80^{c} \\
d r=97: 3\end{array}$ \\
\hline 7 & & n-Butyl-MgCl & $\begin{array}{l}74^{c} \\
d r=95: 5\end{array}$ \\
\hline 8 & & n-Octyl-MgCl & $92^{c}$ \\
\hline 9 & & n-Butyl-MgCl & $65^{c}$ \\
\hline 10 & & n-Butyl-MgCl & $81^{b}$ \\
\hline 11 & & & $72^{b}$ \\
\hline 12 & & & $80^{b}$ \\
\hline 13 & & $-\mathrm{MaBr}$ & $70^{b}$ \\
\hline
\end{tabular}
hexyl Halides using 2 as Catalyst ${ }^{a}$
${ }^{a}$ Reactions were performed on a $0.5 \mathrm{mmol}$ scale. ${ }^{b}$ Isolated yields relative to alkyl halide. ${ }^{c} \mathrm{GC}-\mathrm{MS}$ yields relative to alkyl halide.

As mentioned above, a general limitation of catalyst $\mathbf{1}$ is the inactivity in the coupling of non-activated secondary halides, especially acyclic substrates. Surprisingly, 2 exhibited good efficiency for the Kumada coupling of such substrates with alkyl or aryl Grignard reagents (Table 3). ${ }^{14}$ Acyclic secondary alkyl iodides could not be coupled using $\mathbf{1}$ as catalyst, but were coupled in good yields using 2 as catalyst (Table 3, Entries 1-3, 5-7). Cycloheptyl iodide was coupled in low yield using 1 as catalyst, but the yields were significantly improved using 2 as catalyst (Table 3, Entries 4 and 6). These results confirm that $\mathbf{2}$ is a superior catalyst than $\mathbf{1}$ for the Kumada coupling of alkyl halides.

Table 3. Kumada Coupling of Acyclic Secondary Alkyl Iodides and Cycloheptyl Iodide using 1 or 2 as Catalyst ${ }^{a}$

$\begin{array}{llll}\text { Entry Alkyl Halide } & \begin{array}{l}\text { Grignard Reagent } \\ n \text {-Octyl-MgCl }\end{array} & \begin{array}{l}\text { Yield } \\ \mathbf{1}(\%)\end{array} & \begin{array}{l}\text { Tield } \\ \mathbf{2}(\%)\end{array} \\ 87^{b}\end{array}$


5
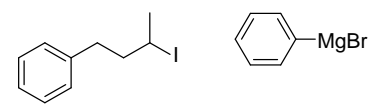

Trace

$60^{c}$

6
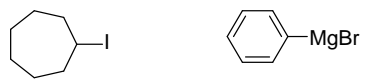

$5^{b}$

$50^{c}$

$18^{b}$

$62^{b}$

7<smiles>CC(C)I</smiles>

$\Longrightarrow-\mathrm{MgBr}$

${ }^{a}$ Reactions were performed on a $0.5 \mathrm{mmol}$ scale. ${ }^{b} \mathrm{GC}$-MS yields relative to alkyl halide. ${ }^{c}$ Isolated yields relative to alkyl halide.

The improved activity of $\mathbf{2}$ in the Kumada coupling encouraged us to further explore its application in other coupling reactions. It was previously shown that $\mathbf{1}$ was active for the Suzuki-Miyaura coupling of primary alkyl halides with 9organo-9-borabicyclo[3.3.1]nonane at $80{ }^{\circ} \mathrm{C} .{ }^{10 a}$ At room temperature, however, the coupling was sluggish.

Complex 2 was tested as catalyst for these Suzuki-Miyaura coupling reactions. Indeed, this catalyst exhibited enhanced activity, allowing the coupling to occur at room temperature (Scheme 3). A secondary alkyl iodide, (3-iodobutyl)benzene was coupled to 9-octyl-9-borabicyclo[3.3.1]nonane and 9phenyl-9-borabicyclo[3.3.1] nonane in good yields. On the contrary, the yields were low or negligible using $\mathbf{1}$ as catalyst under identical conditions (Scheme 3, Eq. 3 and 4).

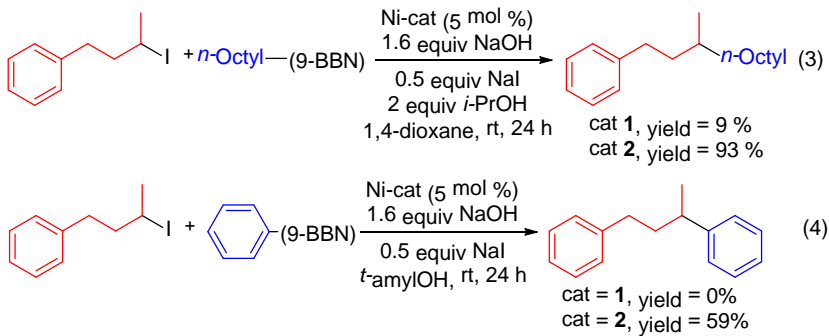

Scheme 3. Suzuki-Miyaura Coupling of a Secondary Alkyl Iodide with 1 and 2

Table 4 shows the scope of the room-temperature SuzukiMiyaura couplings catalyzed by 2. Both alkyl- and aryl-(9$\mathrm{BBN}$ ) reagents could be used as the nucleophilic coupling partners, and both primary and secondary alkyl halides could be coupled.

Table 4. Scope of Suzuki-Miyaura Coupling of Alkyl Halides using 1 or 2 as Catalyst ${ }^{a}$

$\begin{array}{llll}\text { Entry Alkyl Halide } & \begin{array}{l}\mathrm{R}-(9- \\ \mathrm{BBN})\end{array} & \begin{array}{l}\text { Yield } \\ \mathbf{1}(\%)\end{array} & \begin{array}{l}\text { Yield } \\ \mathbf{2}(\%)\end{array} \\ 49^{b} & 82^{c}\end{array}$

6<smiles>CC(I)CCc1ccccc1</smiles>

7<smiles>O=C(c1ccccc1)N1CCC(I)C1</smiles>

8

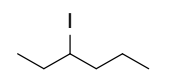

9

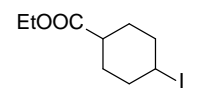

10

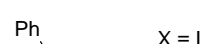

11

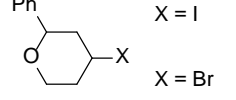

12

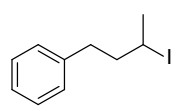

13<smiles>CCCC1=CCCO1</smiles>

Phenyl $\quad 13^{b} \quad 83^{c}$

Trace $68^{c}$

n-Octyl $\quad 9^{b} \quad 53^{b}$

n-Octyl $\quad 31^{b} \quad 86^{c}$

n-Octyl $\quad 50^{b} \quad 80^{c}$

n-Octyl $\quad 47^{b} \quad 74^{c}$

Phenyl $\quad 0^{b} \quad 59^{c}$

${ }^{a}$ Reactions were performed on a $0.5 \mathrm{mmol}$ scale. ${ }^{b} \mathrm{GC}$-MS yields relative to alkyl halide. ${ }^{c}$ Isolated yields relative to alkyl halide.

A variety of functional groups such as pyrrole (Table 4, Entry 1), thiophene (Table 4, Entry 2), ester (Table 4, Entries 3 and 9), ether (Table 4, Entries 4, 10, 11 and 13), carbazole (Table 4, Entry 5), N-Boc (Table 4, Entry 7) and furan (Table 4, Entry 14) were tolerated. In contrast, when 1 was used as catalyst, primary alkyl and cyclohexyl halides were coupled in much lower yields (Table 4, Entries 1 and 13), and the coupling of acylic secondary alkyl halides was generally inefficient (Table 4, Entries 6, 8 and 12). These results further attest the superior activity and broader scope of catalyst $\mathbf{2}$ over catalyst 1.

The significantly enhanced catalytic activity of $\mathbf{2}$ is remarkable given its electronic and structural similarity to $\mathbf{1}$. The pKa and nucleophilicity of pyrrolidino and dimethylamino groups are very close. ${ }^{15}$ To compare the redox properties of $\mathrm{Ni}$ ions in $\mathbf{1}$ and 2, cyclic voltammetry was conducted on [( $\left.{ }^{\mathrm{Pyr}} \mathrm{N}^{\mathrm{Me}} \mathrm{NN}\right) \mathrm{Ni}$ $\left(\mathrm{CH}_{3} \mathrm{CN}\right) \mathrm{PF}_{6}$. One quasi-reversible reduction at $-1.64 \mathrm{~V}$ and one quasi-reversible oxidation at $-0.09 \mathrm{~V}$ vs. ferrocene/ferrocenium was observed (Figure S2). These potentials are only 30 and $60 \mathrm{MV}$ lower than the corresponding potentials for $\left[\left({ }^{\mathrm{Me}} \mathrm{N}_{2} \mathrm{~N}\right) \mathrm{Ni}-\left(\mathrm{CH}_{3} \mathrm{CN}\right)\right] \mathrm{PF}_{6}$. ${ }^{16}$ Given the peak separation of more than $200 \mathrm{mV}$, this small difference suggests similar electronic properties of $\mathbf{1}$ and $\mathbf{2}$. Thus, the activity difference is tentatively assigned to structural factors. The main structural difference between 1 and 2 is the $4^{\circ}$ decrease of the $\mathrm{C}-\mathrm{N}-\mathrm{C}$ angle (see above). This small decrease is apparently sufficient for the access of bulky secondary alkyl halides, which is impossible by catalyst $\mathbf{1}$. Alternatively, the pyrrolidino group might be more "hemilabile" than the dimethylamino group, ${ }^{17}$ thus opening the Ni center during catalysis. To probe the latter possibility, exogenous ligands were added to representative Kumada and Suzuki-Miyaura reactions catalyzed by $\mathbf{2}$ (Scheme 4). 


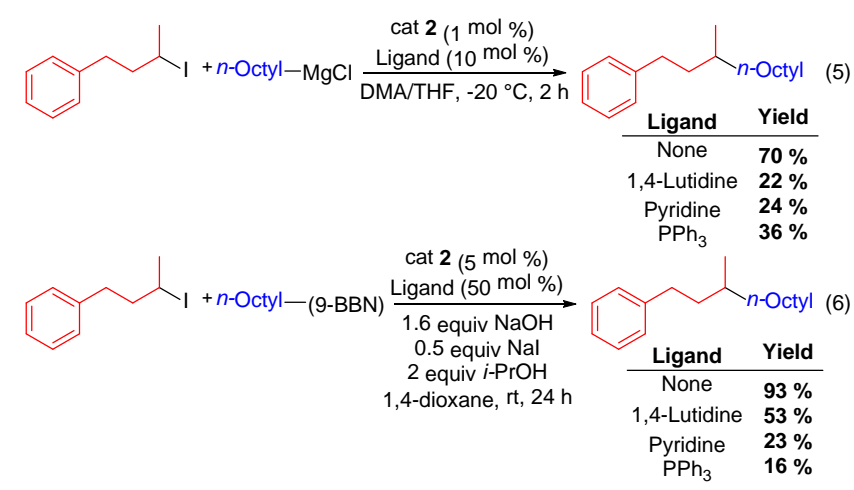

Scheme 4. Effect of the Addition of Exogenous Ligands on Representative Reactions Catalyzed by Complex 2

The addition of 5 equivalent (relative to 2) of an exogenous ligand (lutidine, pyridine, or $\mathrm{PPh}_{3}$ ) to the cross-coupling of the (3-iodobutyl)benzene decreased significantly the yields. These results are consistent with the hypothesis that the pyrrolidino group is "hemilabile and de-coordinate from the $\mathrm{Ni}$ center to create a more open, and thus, accessible reaction site for secondary alkyl halides. ${ }^{12,16}$

In summary, a small modification of the $\mathrm{N}_{2} \mathrm{~N}$ pincer ligand results in a drastically improved $\mathrm{Ni}$ catalyst. The new Ni pincer complex $\mathbf{2}$ is efficient for Kumada and Suzuki-Miyaura coupling of both primary and secondary alkyl halides. Further structural modifications, for example, replacing the second dimethyl amino group by a pyrrolidino group and systematically changing the dimethyl amino groups to 3, 4, 6-membered cyclic amines, will lead to a structure-activity study that gives more insights in the key factors controlling the reactivity of these nickel pincer complexes

\section{ASSOCIATED CONTENT}

Supporting Information. Experimental details and characterization data. This material is available free of charge via the Internet at http://pubs.acs.org.

\section{AUTHOR INFORMATION}

\section{Corresponding Author}

*xile.hu@epfl.ch

\section{Author Contributions}

¥These authors contributed equally.

\section{Notes}

The authors declare no competing financial interests.

\section{ACKNOWLEDGMENT}

This work is supported by the Swiss National Science Foundation (no. 200020_144393/1).

\section{REFERENCES}

(1) Metal-Catalyzed Cross-Coupling Reactions; de Meijere, A., Diederich, F., Eds.; Wiley-VCH: New York, 2004.

(2) (a) Netherton, M. R.; Fu, G. C. Adv. Synth. Catal. 2004, 346 , 1525-1532. (b) Frisch, A. C.; Beller, M. Angew. Chem. Int. Ed. 2005, 44, 674-688. (c) Rudolph, A.; Lautens, M. Angew. Chem. Int. Ed. 2009, 48, 2656-2670. (d) Phapale, V. B.; Cárdenas, D. J. Chem. Soc.
Rev. 2009, 38, 1598-1607. (e) Hu, X. L. Chem. Sci. 2011, 2, 18671886.

(3) For selected recent reviews of transition-metal-catalyzed crosscoupling reactions, see: (a) Jana, R.; Pathak, T. P.; Sigman, M. S. Chem. Rev. 2011, 111, 1417-1492. (b) Kambe, N.; Iwasakia, T.; Terao, J. Chem. Soc. Rev. 2011, 40, 4937-4947. (c) Johansson Seechurn, C. C. C.; Kitching, M. O.; Colacot, T. J.; Snieckus, V. Angew. Chem. Int. Ed. 2012, 51, 5062-5085. (d) Han, F.-S. Chem. Soc. Rev. 2013, 42, 5270-5298.

(4) For selected examples of Fe-catalyzed cross-coupling of nonactivated alkyl halides, see: (a) Sherry, B. D.; Furstner, A. Acc. Chem. Res. 2008, 41, 1500-1511. (b) Hatakeyama, T.; Hashimoto, T.; Kathriarachchi, K. K. A. D. S.; Zenmyo, T.; Seike, H.; Nakamura, M. Angew. Chem. Int. Ed. 2012, 51, 8834-8837. (c) Guisan-Ceinos, M.; Tato, F.; Bunuel, E.; Calle, P.; Cardenas, D. J. Chem. Sci. 2013, 4, 1098-1104. (d) Cheung, C. W.; Ren, P.; Hu, X. L. Org. Lett. 2014, 16, 2566-2569. (e) Bedford, R. B. Acc. Chem. Res. 2015, 48, 1485-1493.

(5) For selected examples of Co-catalyzed cross-coupling of nonactivated alkyl halides, see: (a) Ohmiya, H.; Yorimitsu, H.; Oshima, K. J. Am. Chem. Soc. 2006, 128, 1886-1889. (b) Shukla, P.; Hsu, Y.C.; Cheng, C.-H. J. Org. Chem. 2006, 71, 655-658. (c) Cahiez, G.; Chaboche, C.; Duplais, C.; Giulliani, A.; Moyeux, A. Adv. Synth. Catal. 2008, 350, 1484-1488. (d) Hammann, J. M.; Haas, D.; Knochel, P. Angew. Chem., Int. Ed. 2015, 54, 4478-4481.

(6) For selected recent examples of Ni-catalyzed cross-coupling of non-activated alkyl halides, see: (a) Lu, Z.; Fu, G. C. Angew. Chem. Int. Ed. 2010, 49, 6676-6678. (b) Zultanski, S. L.; Fu, G. C. J. Am. Chem. Soc. 2013, 135, 624-627. (c) Liang, Y.; Fu, G. C. J. Am. Chem. Soc. 2015, 137, 9523-9526. (d) Liang, Y.; Fu, G. C. Angew. Chem. Int. Ed. 2015, 54, 9047-9051. (e) Terao, J.; Kambe, N. Acc. Chem. Res. 2008, 41, 1545-1554.

(7) For selected examples of Cu-catalyzed cross-coupling of nonactivated alkyl halides, see: (a) Yang, C.-T.; Zhang, Z.-Q.; Liu, Y.-C.; Liu, L. Angew. Chem. Int. Ed. 2011, 50, 3904-3907. (b) Ren, P.; Stern, L.-A.; Hu, X. L. Angew. Chem. Int. Ed. 2012, 51, 9110-9113. (c) Yang, C.-T.; Zhang, Z.-Q.; Liang, J.; Liu, J.-H.; Lu, X.-Y.; Chen, H.-H.; Liu, L. J. Am. Chem. Soc. 2012, 134, 11124-11127.

(8) (a) Vechorkin, O.; Hu, X. L. Angew. Chem. Int. Ed. 2009, 48, 2937-2940. (b) Vechorkin, O.; Proust, V.; Hu, X. L. J. Am. Chem. Soc. 2009, 131, 9756-9766. (c) Perez Garcia, P. M.; Di Franco, T.; Orsino, A.; Ren, P.; Hu, X. L. Org. Lett. 2012, 14, 4286-4289.

(9) (a) Vechorkin, O.; Barmaz, D.; Proust, V.; Hu, X. L. J. Am. Chem. Soc. 2009, 131, 12078-12079. (b) Vechorkin, O.; Godinat, A.; Scopelliti, R.; Hu, X. L. Angew. Chem. Int. Ed. 2011, 50, 1177711781.

(10) (a) Di Franco, T.; Boutin, N.; Hu, X. L. Synthesis 2013, 45, 2949-2958. (b) Di Franco, T.; Epenoy, A.; Hu, X. L. Org. Lett. 2015, 17, 4910-4913.

(11) Vechorkin, O.; Proust, V.; Hu, X. L. Angew. Chem. Int. Ed. 2010, 49, 3061-3064.

(12) Ren, P.; Vechorkin, O.; von Allmen, K.; Scopelliti, R.; Hu, X. L. J. Am. Chem. Soc. 2011, 133, 7084-7095.

(13) For crystallographic details of complex 2, see the Supporting Information.

(14) For practical convenience, catalyst loading was $3.5 \mathrm{~mol} \%$ for the Kumada coupling reactions shown in Table 2. However, a catalyst loading of $1 \mathrm{~mol} \%$ is sufficient to obtain the cross-coupling products in the same yields.

(15) Mayr, H.; Ofial, A. R. J. Phys. Org. Chem. 2008, 21, 584-595.

(16) Vechorkin, O.; Csok, Z.; Scopelliti, R.; Hu, X. L. Chem. Eur. J. 2009, 15, 3889-3899.

(17) Perez García, P. M.; Ren, P.; Scopelliti, R.; Hu, X. L. ACS Catal. 2015, 5, 1164-1171. 


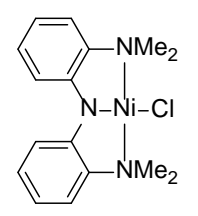

Cat. 1

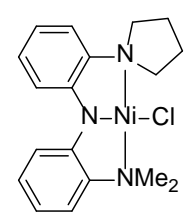

Cat. 2

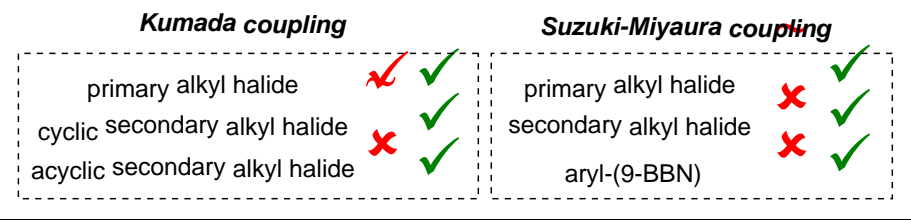

